\title{
Metronomic treatment of advanced non-small-cell lung cancer with daily oral vinorelbine - a Phase I trial
}

\author{
Sylvia Guetz ${ }^{1, *}$ \\ Amanda Tufman ${ }^{2, *}$ \\ Joachim von Pawel $^{3}$ \\ Achim Rittmeyer ${ }^{4}$ \\ Astrid Borgmeier ${ }^{2}$ \\ Pierre Ferré ${ }^{5}$ \\ Birgit Edlich ${ }^{6}$ \\ Rudolf Maria Huber ${ }^{2}$ \\ 'Ev. Diakonissenkrankenhaus \\ Leipzig, Leipzig, ${ }^{2}$ University Hospital \\ Munich and Thoracic Oncology \\ Centre Munich, Member of the \\ German Center for Lung Research, \\ Comprehensive Pneumology \\ Center Munich (DZL CPC-M), \\ Munich, ${ }^{3}$ Asklepios Fachkliniken \\ Muenchen-Gauting, Gauting, \\ ${ }^{4}$ Lungenfachklinik Immenhausen, \\ Immenhausen, Germany; ${ }^{5}$ Pierre Fabre \\ Pharmaceuticals, Oncology Research \\ and Development Center, Toulouse, \\ France; ${ }^{6}$ Pierre Fabre Pharma GmbH, \\ Freiburg, Germany \\ *These authors contributed equally \\ to this work
}

This article was published in the following Dove Press journal:

OncoTargets and Therapy

21 February 2017

Number of times this article has been viewed

Micro-abstract: In a Phase I dose-finding study of metronomic daily oral vinorelbine in advanced non-small-cell lung cancer, a recommended dose was established for this therapeutic approach. In addition, this trial revealed promising efficacy data and an acceptable tolerability profile. The observed vinorelbine blood concentrations suggest continuous antiangiogenic coverage.

Introduction: We present a Phase I dose-finding study investigating metronomic daily oral vinorelbine (Navelbine ${ }^{\circledR}$ Oral, NVBo) in advanced non-small-cell lung cancer (NSCLC).

Patients and methods: Patients with stage III/IV NSCLC received daily NVBo at fixed dose levels of $20-50 \mathrm{mg} / \mathrm{d}$ for 21 days of each 4-week cycle. Primary end point was the maximum tolerated dose. Secondary end points included tumor response, time to progression (TTP), overall survival (OS) and tolerability.

Results: Twenty-seven patients with advanced NSCLC were enrolled. Most of them were extensively pretreated. Daily NVBo was well tolerated up to $30 \mathrm{mg} / \mathrm{d}$. At $40 \mathrm{mg} / \mathrm{d}$, two of five patients experienced dose-limiting toxicities (DLTs). Three of six patients had DLTs at the $50 \mathrm{mg} / \mathrm{d}$ level. The recommended dose was established at $30 \mathrm{mg} / \mathrm{d}$ in cycle 1, with escalation to $40 \mathrm{mg} / \mathrm{d}$ in cycle 2, if tolerated. Pharmacokinetic analyses showed continuous blood exposure over 21 days and only marginal accumulation. The tolerability profile was acceptable (all dose levels - all grades: decreased appetite 33\%, diarrhea 33\%, leukopenia 33\%, nausea $30 \%$, vomiting $26 \%$; $\geq$ grade 3 : leukopenia $30 \%$, lymphopenia $19 \%$, neutropenia $19 \%$, febrile neutropenia 15\%). Disease control rate, OS and TTP signaled a treatment effect.

Conclusion: Daily metronomic NVBo therapy in extensively pretreated patients with advanced NSCLC is feasible and safe at the recommended dose of $30 \mathrm{mg} / \mathrm{d}$. Escalation to $40 \mathrm{mg} / \mathrm{d}$ in the second cycle is possible. The blood concentrations of vinorelbine after daily metronomic dosing reached lower peaks than intravenous or oral conventional dosing. Blood concentrations were consistent with anti-angiogenic or immune modulating pharmacologic properties of vinorelbine. Further studies are warranted to evaluate the safety and efficacy of this novel approach in specific patient populations.

Keywords: NSCLC, dose escalation, lung carcinoma, vinca-alkaloid, anti-angiogenic treatment, cytotoxic therapy, vinorelbine capsules

\section{Introduction}

Lung cancer remains a major burden to patients and their communities. With 1.8 million new cases and 1.59 million deaths in 2012, lung cancer is one of the most common, and most fatal, cancers worldwide. ${ }^{1,2}$

Non-small-cell lung cancer (NSCLC) accounts for $>80 \%$ of lung cancer cases. Although patients with early-stage disease may be cured by surgical resection, most $\mathrm{BY} \mathrm{NC}$ and incorporate the Creative Commons Attribution - Non Commercial (unported, v3.0) License (http://creativecommons.org/licenses/by-nc/3.0/). By accessing the work you
hereby accept the Terms. Non-commercial uses of the work are permitted without any further permission from Dove Medical Press Limited, provided the work is properly attributed. For permission for commercial use of this work, please see paragraphs 4.2 and 5 of our Terms (https://www.dovepress.com/terms.php). 
patients with NSCLC present with advanced, inoperable disease. These patients, in particular those whose tumors do not respond to treatment, have a poor prognosis. ${ }^{3,4}$

Vinorelbine, a semisynthetic vinca-alkaloid, has demonstrated a good safety profile and consistent treatment efficacy across randomized trials in advanced NSCLC. ${ }^{5-9}$ The combination of cisplatin and vinorelbine is considered a standard of care in this setting. ${ }^{10-12}$

Most cytotoxic chemotherapy treatments are administered intravenously (iv). In NSCLC, single doses of iv chemotherapeutics are often administered on the first day of each 3- or 4-week cycle or more frequently, for example, on a weekly basis.

However, as the availability of oral cancer treatments increases, ${ }^{13}$ potential advantages of this form of dosing are becoming clear. In addition to eliminating the discomfort, stress and potential complications associated with iv lines, ${ }^{14}$ oral treatments can be administered at home, increasing convenience for patients and reducing the costs associated with visits to chemotherapy clinics. ${ }^{15,16}$ Oral treatments may be administered frequently without the burden associated with repeated infusions or continuous chemotherapy pumps.

Metronomic low-dosing schedules made possible by oral formulations may have biologic advantages compared to conventional chemotherapy boluses. The pharmacokinetics (PK) of metronomic administration allow for constant exposure to the cytotoxic agent, which may prevent tumor regrowth that may otherwise happen between conventional chemotherapy cycles. Furthermore, the toxic effects of chemotherapy might be lessened due to lower peak plasma concentrations. In addition, metronomic chemotherapy has been described to mediate antitumor effects by mechanisms other than cytotoxicity. The frequent administration of lowdose chemotherapy can induce anti-angiogenic effects, target tumor vasculature and strengthen the antitumor immune response by suppressing regulatory $\mathrm{T}$ cells and inducing the maturation of dendritic cells. ${ }^{17,18}$ Metronomic treatment strategies in various tumor entities were recently reviewed by Bocci and Kerbel ${ }^{19}$ in Nature Reviews. These authors emphasized the importance of including PK data in studies of metronomic chemotherapy in order to better understand dosing and treatment effects.

Oral vinorelbine (Navelbine ${ }^{\circledR}$ soft capsules; Pierre Fabre Médicament, Boulogne Billancourt, France; NVBo) has similar cytotoxic activity to iv vinorelbine. ${ }^{20-22}$ Initially, mimicking iv regimens, NVBo was given weekly ${ }^{23,24}$; however, taking advantage of the oral formulation, more frequent and metronomic dosing has been recently introduced. Previous studies have shown that the administration of NVBo three times per week is feasible and well tolerated. ${ }^{25,26}$ Preliminary data indicate that fractionated doses of $70 \mathrm{mg} / \mathrm{m}^{2} / \mathrm{wk}$ split over days 1, 3 and 5 as well as fixed doses of up to $60 \mathrm{mg}$ every other day are well tolerated and show activity in some patients..$^{27,28}$

In this Phase I clinical trial, tolerability and preliminary efficacy of a metronomic treatment schedule, using fixed daily doses of 20-50 mg NVBo administered for 21 consecutive days of a 28-day cycle, were investigated in extensively pretreated patients with advanced NSCLC.

\section{Patients and methods Study design and objectives}

This open-label Phase I clinical study recruited patients from April 2007 to December 2011. The primary objective was to determine the maximum tolerated dose (MTD) of daily NVBo. Secondary end points included tumor response, time to progression (TTP), overall survival (OS), tolerability profile and pharmacokinetic parameters. Adverse events (AEs) were graded according to Common Terminology Criteria for Adverse Events v3.0.29. ${ }^{29}$

\section{Patients and study centers}

Eligible patients were at least 18 years old and had histologically or cytologically confirmed stage IIIB/IV NSCLC (TNM 6) or recurrent disease after local therapy, with an indication for palliative chemotherapy. Both previously untreated patients and those who had received treatment with one or more lines of systemic therapy were eligible for inclusion. Patients were eligible if they had at least one measurable lesion (Response Evaluation Criteria in Solid Tumors [RECIST] $\mathrm{v} 1.0^{30}$ ), a Karnofsky index of at least $70 \%$, a life expectancy of at least 12 weeks and adequate organ function.

Patients were excluded if they had metastases of the central nervous system, superior vena cava syndrome, symptomatic sensory neuropathy greater than grade 1 or any concomitant uncontrolled medical disorder. Moreover, patients could not have received previous treatment with vinorelbine and were required to be off systemic treatments and radiation for 30 days prior to enrollment. The study was conducted in four German centers.

\section{Treatment}

The patients were treated at four dose levels: 20, 30, 40 and $50 \mathrm{mg} / \mathrm{d}$ NVBo administered as levels I, II, III and IV, respectively. One treatment cycle was defined as a 28-day period, with daily administration on days 1-21 followed by 
a 7-day treatment-free interval. This schedule was selected to limit potential accumulation and associated toxicity.

In the dose escalation phase of the study, a $3+3$ dose escalation design was applied. Three to six patients were treated at each dose level before escalation to the next dose level. The MTD was defined at the dose level, where at least two of six patients experienced dose-limiting toxicities (DLTs); the level below the MTD was defined as recommended dose for further evaluation. DLTs were assessed during cycle 1 at dose levels I-III. At dose level IV, the study was amended in order to include cycles 1 and 2 in the DLT assessment based on events fulfilling DLT criteria observed in cycle 2. DLTs were defined as follows: fever (with or without clinical infection), three elevations of oral temperature to $>38^{\circ} \mathrm{C}$ during a 24-hour period or a single elevation in oral temperature to $>38.5^{\circ} \mathrm{C}$ concomitant with grade 4 neutropenia and requiring iv antibiotics and/or hospitalization; grade 4 neutropenia and/or grade 2 thrombocytopenia lasting for $\geq 7$ days; grade 4 or symptomatic grade 3 thrombocytopenia and any non-hematological event higher than grade 2 (excluding nausea/vomiting and AEs considered unrelated to treatment).

After MTD identification, it was planned to enroll a maximum of 12 patients at the recommended dose level. Due to slow accrual, only seven patients were included at this level.

\section{PK assessment}

Vinorelbine blood levels were assessed on days 1 and 21 of cycle 1 , with additional trough levels on days 8 and 15 . Blood concentrations of vinorelbine and its only active metabolite 4-O-deacetylvinorelbine (DVRL) were quantified using a fully validated liquid chromatography-tandem mass spectrometry with a lower limit of quantification of $0.25 \mathrm{ng} / \mathrm{mL}$. PK parameters, such as the area under the plasma drugconcentration time curve (AUC), were calculated by a modelindependent approach using KINETICA ${ }^{\circledR}$ software (Thermo Fischer Scientific Inc., Waltham, MA, USA). Median AUC estimates were used to calculate the accumulation ratio based on exposure $\left(\mathrm{R}_{\mathrm{AUC}}\right)$. The accumulation ratios based on trough concentration levels at days $1,8,15$ and $21\left(\mathrm{R}_{\text {Ctrough }}\right)$ were calculated as well.

\section{Efficacy assessment}

Standard imaging was performed after every second cycle. Assessments of tumor response were performed according to RECIST v1.0. After treatment discontinuation, patients were followed up every 3 months until death.

\section{Statistics}

Data were evaluated using $\mathrm{SAS}^{\circledR}$ version 9.2 (Cary, NC, USA). Standard descriptive methods were used for all corresponding data. Time-to-event parameters were analyzed using the Kaplan-Meier method.

Duration of disease control (DoDC) was measured from the start of treatment until progression or death in patients with response or stable disease. TTP was calculated from the start of treatment until progression. If progression or death did not occur during treatment or within 30 days after treatment termination, patients were censored with the date of the last tumor assessment. Survival was measured from the start of treatment until death. Patients who were alive or lost to follow-up were censored with the last date they were known to be alive.

\section{Ethical principles}

All patients provided written informed consent. Approval of the study was obtained from the responsible ethics committee (ethics committee of the Medical Department LudwigMaximilians-University Munich) and regulatory authority (Bundesinstitut für Arzneimittel und Medizinprodukte). The study was conducted in accordance with the Declaration of Helsinki, Good Clinical Practice guidelines and local ethical and legal requirements.

\section{Results Analysis populations}

Twenty-seven patients were enrolled in the study; all patients received study treatment. The safety population (SAF) included all 27 patients and was identical with the intentto-treat population (ITT). In addition, the following populations were analyzed: patients evaluable for response (RESP; 21 patients), patients evaluable for MTD (17 patients) and patients treated at the recommended dose level (RD; seven patients). The study population is summarized in a Consort diagram (Figure 1).

\section{Baseline parameters and disease characteristics}

Of the 27 enrolled patients, 55.6\% were male. Patient age ranged between 49 and 78 years (median: 65 years). Most patients $(63.0 \%)$ had a Karnofsky index of $70 \%-80 \%$. The median time from the first NSCLC diagnosis until enrollment was 20.7 months (range: $0.4-78.5$ months). The distribution of histology was $44.4 \%$ for squamous cell carcinoma and $55.6 \%$ for adenocarcinoma. A total of $22.2 \%$ and $77.8 \%$ of patients were classified as stages IIIB and IV at study entry, respectively. At the time of baseline assessment, all patients had 


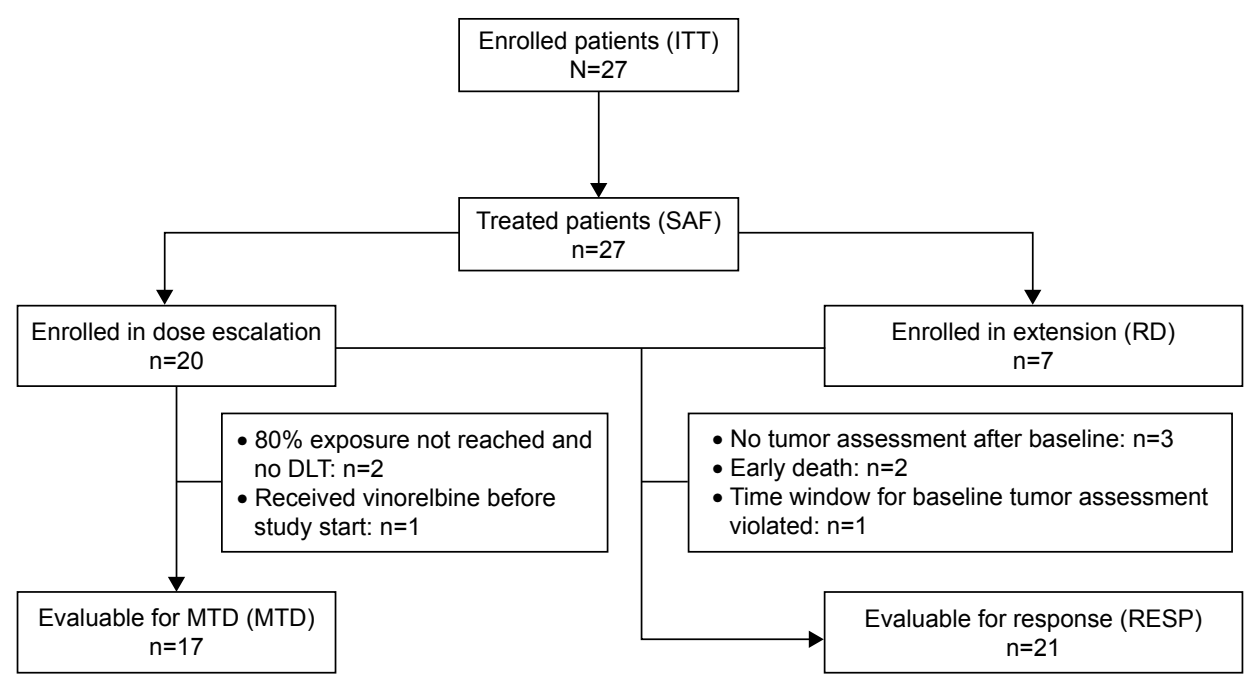

Figure I Consort diagram.

Abbreviations: DLT, dose-limiting toxicity; ITT, intention-to-treat population; MTD, maximum tolerated dose population; RD, recommended dose population; RESP, response population; SAF, safety population.

liver metastases: additional baseline tumor locations included lymph nodes (40.7\%), pleura (33.3\%) and bone (18.5\%). Nearly all patients had received prior chemotherapy $(92.6 \%)$ mainly in palliative intention (77.8\%); the median number of prior palliative treatment lines was 3 (range: 0-5). About half of the patients $(51.9 \%)$ had prior radiotherapy. Demographic data and disease characteristics are shown in Table 1.

\section{Study treatment}

The enrolled patients received a median of two treatment cycles (range: 1-33 cycles). The median treatment duration, absolute dose and relative dose intensity were 48 days (range: 3-912 days), 1,290 mg (range: 90-33,750 mg) and $97.9 \%$ (range: $40.0 \%-105.8 \%$ ), respectively. The main reason for treatment discontinuation was progression or death (85.2\%); discontinuations due to AEs occurred in $11.1 \%$ of the patients.

\section{Maximum tolerated dose}

A total of 17 patients were evaluable for MTD. Table 2 provides a detailed overview on the dose escalation phase. At dose level III (40 mg/d), one of three patients experienced a DLT (neutropenia) in cycle 2, that is, after the protocol-specified DLT observation period. At dose level IV $(50 \mathrm{mg} / \mathrm{d})$, two of six patients showed DLTs during cycle 1 (fever and neutropenia) and one patient experienced DLTs during cycle 2 (fever and non-hematological event). Accordingly, the MTD was reached at dose level IV, and recruitment was extended at the draft recommended dose of $40 \mathrm{mg} / \mathrm{d}$. However, one additional patient experienced a DLT during cycle 1 at this dose (fever).
Therefore, the following dose regimen was finally defined as recommended schedule for further assessment: $30 \mathrm{mg} / \mathrm{d}$ NVBo in cycle 1; escalation to $40 \mathrm{mg} / \mathrm{d}$ from cycle 2 , if no DLT occurred during cycle 1 . A total of seven patients were treated with this recommended schedule.

\section{Pharmacokinetics}

Cycle $1 \mathrm{PK}$ could be assessed in a total of 21 patients. However, five of these patients were considered as non-evaluable on at least one of the PK days. Blood concentrations of vinorelbine generally increased with escalating dose levels. At 30 and $40 \mathrm{mg}$ (Figure 2), the daily oral dosing of vinorelbine provided a continuous blood exposure, as median trough concentrations were all $>1 \mathrm{ng} / \mathrm{mL}$.

A marginal accumulation of vinorelbine was observed until day 8 based on residual concentrations (median $\mathrm{R}_{\text {Ctrough }}$ ranged from 1.96 to 2.03 between day 1 and either day 8,15 or 21, all dose levels). This had no impact on global exposure over repeated dosing, as only minor differences in blood exposure were detected between days 1 and 21 (median $\mathrm{R}_{\mathrm{AUC}}$ day 21/day 1: 0.8, 1.6, 1.8 and 0.7 at 20, 30, 40 and $50 \mathrm{mg} / \mathrm{d}$, respectively).

For DVRL, concentrations on day 1 were either not quantifiable or near the lower limit of quantitation for all patients. On day 21, DVRL concentrations were approximately or $<1 \mathrm{ng} / \mathrm{mL}$. As a result, no DVRL accumulation ratio could be calculated.

\section{Tolerability}

Of the 27 treated patients, $26(96.3 \%)$ patients experienced at least one adverse event and $20(74.1 \%)$ patients had at least 
Table I Demographic data and disease characteristics

\begin{tabular}{|c|c|c|c|c|}
\hline Characteristics & ITT/SAF (n=27) & $\operatorname{RESP}(n=2 I)$ & MTD (n=I7) & $\operatorname{RD}(n=7)$ \\
\hline \multicolumn{5}{|l|}{ Gender } \\
\hline Male & 15 (55.6\%) & II (52.4\%) & $10(58.8 \%)$ & $2(28.6 \%)$ \\
\hline Female & 12 (44.4\%) & $10(47.6 \%)$ & 7 (4I.2\%) & $5(71.4 \%)$ \\
\hline \multicolumn{5}{|l|}{ Age (years) } \\
\hline Mean \pm StD (median) & $65 \pm 8(65)$ & $63 \pm 8(64)$ & $64 \pm 8(64)$ & $68 \pm 8(69)$ \\
\hline \multicolumn{5}{|l|}{ Body surface area $\left(\mathrm{m}^{2}\right)$} \\
\hline Mean \pm StD (median) & $1.9 \pm 0.3(1.9)$ & $1.9 \pm 0.3(1.9)$ & $1.8 \pm 0.2(1.9)$ & $1.8 \pm 0.2(1.7)$ \\
\hline \multicolumn{5}{|l|}{ Karnofsky index } \\
\hline $70 \%$ & $6(22.2 \%)$ & $3(14.3 \%)$ & $2(11.8 \%)$ & $3(42.9 \%)$ \\
\hline $80 \%$ & II (40.7\%) & $9(42.9 \%)$ & $8(47.1 \%)$ & $2(28.6 \%)$ \\
\hline $90 \%$ & $7(25.9 \%)$ & $6(28.6 \%)$ & $5(29.4 \%)$ & I (14.3\%) \\
\hline $100 \%$ & $3(11.1 \%)$ & $3(14.3 \%)$ & $2(11.8 \%)$ & I (14.3\%) \\
\hline \multicolumn{5}{|l|}{ Smoking status } \\
\hline Never & $6(22.2 \%)$ & $5(23.8 \%)$ & 5 (29.4\%) & I (I4.3\%) \\
\hline Former & $8(29.6 \%)$ & $6(28.6 \%)$ & $4(23.5 \%)$ & $2(28.6 \%)$ \\
\hline Current & $7(25.9 \%)$ & $7(33.3 \%)$ & $5(29.4 \%)$ & $2(28.6 \%)$ \\
\hline Missing information & $6(22.2 \%)$ & $3(14.3 \%)$ & $3(17.6 \%)$ & $2(28.6 \%)$ \\
\hline \multicolumn{5}{|l|}{ Histology } \\
\hline Squamous cell carcinoma & $12(44.4 \%)$ & II (52.4\%) & $10(58.8 \%)$ & I (I4.3\%) \\
\hline Adeno carcinoma & $13(48.1 \%)$ & $9(42.9 \%)$ & $6(35.3 \%)$ & $6(85.7 \%)$ \\
\hline Adeno (bronchoalveolar) & $2(7.4 \%)$ & I (4.8\%) & I (5.9\%) & 0 \\
\hline \multicolumn{5}{|l|}{ Tumor stage at study entry } \\
\hline $\mathrm{IIIB}^{\mathrm{a}}$ & $6(22.2 \%)$ & $6(28.6 \%)$ & $6(35.3 \%)$ & 0 \\
\hline IV & $21(77.8 \%)$ & $15(71.4 \%)$ & $\mathrm{II}(64.7 \%)$ & $7(100 \%)$ \\
\hline Previous surgery for primary tumor & $3(11.1 \%)$ & $2(9.5 \%)$ & $2(11.8 \%)$ & $\mathrm{I}(14.3 \%)$ \\
\hline Prior chemotherapy & $25(92.6 \%)$ & $20(95.2 \%)$ & $16(94.1 \%)$ & $7(100 \%)$ \\
\hline Neoadjuvant & $\mathrm{I}(3.7 \%)$ & I $(4.8 \%)$ & $\mathrm{I}(5.9 \%)$ & 0 \\
\hline Adjuvant & $3(11.1 \%)$ & $2(9.5 \%)$ & I (5.9\%) & $2(28.6 \%)$ \\
\hline Curative & $4(14.8 \%)$ & $4(19.0 \%)$ & $3(17.6 \%)$ & 0 \\
\hline Palliative & $21(77.8 \%)$ & $17(81.0 \%)$ & $15(88.2 \%)$ & $5(71.4 \%)$ \\
\hline Prior palliative lines, median (range) & $3(0-5)$ & $3(0-5)$ & $3(0-5)$ & $2(I-3)$ \\
\hline Prior radiation & $14(51.9 \%)$ & $1 \mathrm{I}(52.4 \%)$ & $9(52.9 \%)$ & $4(57.1 \%)$ \\
\hline
\end{tabular}

Notes: Data were represented as $\mathrm{n}$ (\% of patients). ${ }^{\mathrm{a} O n e}$ of the patients had recurrence after local therapy.

Abbreviations: ITT, intention-to-treat population; MTD, maximum tolerated dose population; RD, recommended dose population; RESP, response population; SAF, safety population; StD, standard deviation.

one event with potential relationship to NVBo (Table 3).

The most frequently reported related events were decreased appetite (33.3\%), diarrhea (33.3\%), leukopenia (33.3\%), nausea $(29.6 \%)$ and vomiting $(25.9 \%)$. The most frequently reported related AEs of grade 3 or higher were leukopenia (29.6\%), lymphopenia (18.5\%), neutropenia (18.5\%) and febrile neutropenia (14.8\%). In the RD population $(n=7)$, the most frequently reported related events were decreased appetite (42.9\%) and vomiting (28.6\%).

Serious AEs were observed in 17 (63.0\%) patients of the SAF, and in $8(29.6 \%)$ of those patients, the event was rated as potentially related to NVBo. The latter included

Table 2 Dose escalation - DLTs observed during the dose escalation phase of the trial including toxicities observed at the MTD

\begin{tabular}{|c|c|c|c|c|c|c|c|}
\hline Dose level & $\begin{array}{l}\text { Number } \\
\text { of patients } \\
\text { enrolled }\end{array}$ & $\begin{array}{l}\text { Number } \\
\text { of patients } \\
\text { with DLT }\end{array}$ & $\begin{array}{l}\text { Cycle with } \\
\text { DLT }\end{array}$ & $\begin{array}{l}\text { DLT } \\
\text { fever }\end{array}$ & $\begin{array}{l}\text { DLT } \\
\text { neutropenia }\end{array}$ & $\begin{array}{l}\text { DLT } \\
\text { thrombocytopenia }\end{array}$ & $\begin{array}{l}\text { DLT non- } \\
\text { hematological }\end{array}$ \\
\hline Level I (20 mg/d) & 3 & 0 & - & - & - & - & - \\
\hline Level II (30 mg/d) & 3 & 0 & - & - & - & - & - \\
\hline Level III (40 mg/d) & 3 & 1 & $2(n=1)^{a}$ & - & I & - & - \\
\hline Level IV $(50 \mathrm{mg} / \mathrm{d})=$ MTD & 6 & 3 & I $(n=2), 2(n=I)$ & 3 & I & - & I \\
\hline Draft RD $(40 \mathrm{mg} / \mathrm{d})^{\mathrm{b}}$ & 2 & I & $I(n=I)$ & I & - & - & - \\
\hline
\end{tabular}

Notes: Based on these results, the extension phase was initiated with a recommended dose of $30 \mathrm{mg}$ vinorelbine/d and the option to increase to $40 \mathrm{mg} / \mathrm{d}$ in individual patients. ${ }^{a}$ At that time, only cycle I was taken into account for DLT assessment; the study design was amended from level IV taking now into account cycles I and 2. ${ }^{b}$ After recruitment of two further patients at this draft RD level, one patient experienced a DLT during cycle I. Earlier, on the same dose (see level III) another patient had experienced a DLT during cycle 2 . As a total of two of five patients had experienced DLTs at $40 \mathrm{mg} / \mathrm{d}$, it was concluded that the final recommended dose level should range between 30 and $40 \mathrm{mg}$, rather than to follow a strict $40 \mathrm{mg}$ dose.

Abbreviations: $d$, days; DLT, dose-limiting toxicity; MTD, maximum tolerated dose; RD, recommended dose. 


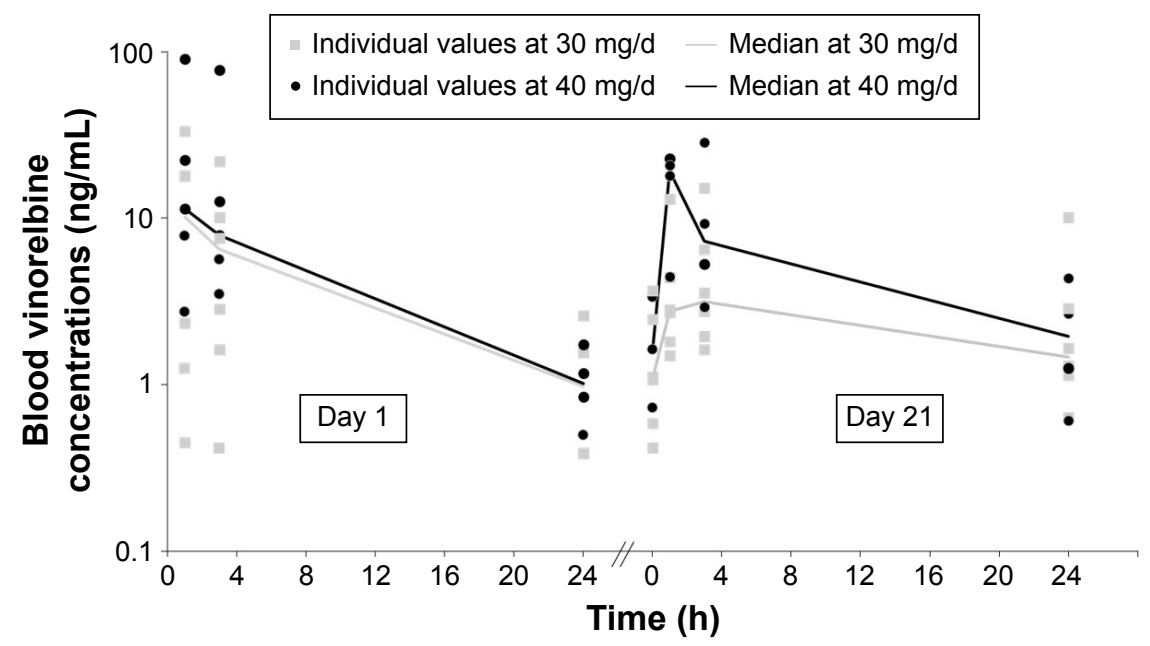

Figure 2 Vinorelbine blood concentrations on day I and day 2 I (cycle I) after daily dosing of oral vinorelbine. Abbreviations: d, day; h, hours.

the following cases: at dose level II $(30 \mathrm{mg} / \mathrm{d})$, one patient experienced grade 3 anorexia. At level III (40 mg/d), one patient experienced grade 4 febrile neutropenia and another patient grade 3 nausea. At level IV $(50 \mathrm{mg} / \mathrm{d})$, one patient experienced grade 4 leukopenia and grade 4 febrile neutropenia, one patient grade 4 neutropenic sepsis and another

Table 3 AEs potentially related to vinorelbine occurring in at least $10 \%$ of the SAF and/or RD population

\begin{tabular}{|c|c|c|c|c|}
\hline \multirow{2}{*}{$\begin{array}{l}\text { AE, } \\
\text { n (\% patients) }\end{array}$} & \multicolumn{2}{|l|}{ SAF $(n=27)$} & \multicolumn{2}{|l|}{$\operatorname{RD}(n=7)$} \\
\hline & Any grade & $\geq$ Grade 3 & Any grade & $\geq$ Grade 3 \\
\hline Any event & $20(74.1 \%)$ & II (40.7\%) & $3(42.9 \%)$ & $2(28.6 \%)$ \\
\hline \multicolumn{5}{|c|}{ Hematological events } \\
\hline Leukopenia & $9(33.3 \%)$ & $8(29.6 \%)$ & I (I4.3\%) & I (I4.3\%) \\
\hline Lymphopenia & $6(22.2 \%)$ & $5(18.5 \%)$ & I (14.3\%) & I (I4.3\%) \\
\hline Neutropenia & $5(18.5 \%)$ & $5(18.5 \%)$ & I (I4.3\%) & I (I4.3\%) \\
\hline $\begin{array}{l}\text { Febrile } \\
\text { neutropenia }\end{array}$ & $4(14.8 \%)$ & $4(14.8 \%)$ & I (I4.3\%) & I (I4.3\%) \\
\hline \multicolumn{5}{|c|}{ Non-hematological events } \\
\hline $\begin{array}{l}\text { Decreased } \\
\text { appetite }\end{array}$ & $9(33.3 \%)$ & 0 & $3(42.9 \%)$ & 0 \\
\hline Diarrhea & 9 (33.3\%) & 0 & I (I4.3\%) & 0 \\
\hline Nausea & $8(29.6 \%)$ & I (3.7\%) & I (I4.3\%) & 0 \\
\hline Vomiting & 7 (25.9\%) & 0 & $2(28.6 \%)$ & 0 \\
\hline Fatigue & $5(18.5 \%)$ & I (3.7\%) & I (14.3\%) & 0 \\
\hline Dizziness & $4(14.8 \%)$ & 0 & 0 & 0 \\
\hline Asthenia & $3(11.1 \%)$ & 0 & I (I4.3\%) & 0 \\
\hline Constipation & $3(11.1 \%)$ & 0 & 0 & 0 \\
\hline $\begin{array}{l}\text { Weight } \\
\text { decreased }\end{array}$ & $3(11.1 \%)$ & 0 & 0 & 0 \\
\hline Colitis & I (3.7\%) & I (3.7\%) & I (14.3\%) & I (I4.3\%) \\
\hline Pneumonia & I (3.7\%) & I (3.7\%) & I (14.3\%) & I (I4.3\%) \\
\hline Sepsis & I (3.7\%) & I (3.7\%) & I (14.3\%) & I (14.3\%) \\
\hline
\end{tabular}

Abbreviations: $A E$, adverse event; RD, recommended dose population; SAF, safety population. patient grade 4 leukopenia. At the recommended dose level (30-40 mg/d), one patient showed grade 2 vomiting and another patient experienced grade 4 febrile neutropenia, grade 4 pneumonia, grade 4 sepsis and grade 5 colitis. The latter patient was 74 years old, had several comorbidities (including hypertension, coronary heart disease and pulmonary embolism), was extensively pretreated (adenocarcinoma stage IV, two prior treatments with pemetrexed plus cisplatin followed by erlotinib) and experienced these events at the end of cycle $2(40 \mathrm{mg} / \mathrm{d})$. The management of this case was further complicated by the patients' delayed reporting of the early symptoms and initial refusal to be admitted for treatment, so that treatment could not be delivered effectively.

\section{Efficacy}

In this heavily pretreated population, none of the patients experienced complete or partial response (Table 4). Four patients showed stable disease during the study, resulting in a disease control rate (DCR) of $19.0 \%$ in the RESP population ( $\mathrm{n}=21)$. Kaplan-Meier analysis revealed a median DoDC of 8.7 months (95\% confidence interval [95\% CI]: 4.9-27.3 months) in the patients with stable disease.

In the intent-to-treat population $(\mathrm{n}=27)$, the median TTP and OS were 1.7 months (95\% CI: 1.4-2.1 months) and 5.7 months (95\% CI: 3.5-9.6 months), respectively.

\section{Discussion}

Metronomic chemotherapy is characterized by continuous long-term administration of chemotherapeutics at relatively low doses. ${ }^{17}$ Potential advantages of this form of dosing include lower toxicity, avoidance of drug resistance and anti-angiogenic effects. ${ }^{18,31}$ In recent years, preclinical and 
Table 4 Efficacy parameters

\begin{tabular}{|c|c|c|c|}
\hline n (\% patients) & $\begin{array}{l}\text { ITT/SAF } \\
(n=27)\end{array}$ & $\begin{array}{l}\text { RESP } \\
(n=21)\end{array}$ & $\begin{array}{l}\text { RD } \\
(n=7)\end{array}$ \\
\hline \multicolumn{4}{|l|}{ Tumor response (RECIST) } \\
\hline $\mathrm{CR}$ & 0 & 0 & 0 \\
\hline PR & 0 & 0 & 0 \\
\hline SD & $4(14.8 \%)$ & $4(19.0 \%)$ & I (I4.3\%) \\
\hline PD & $17(63.0 \%)$ & $17(81.0 \%)$ & $3(42.9 \%)$ \\
\hline Not evaluable & $6(22.2 \%)$ & 0 & $3(42.9 \%)$ \\
\hline ORR $(C R+P R)$ & 0 & 0 & 0 \\
\hline $\mathrm{DCR}(\mathrm{CR}+\mathrm{PR}+\mathrm{SD})$ & $4(14.8 \%)$ & $4(19.0 \%)$ & I (I4.3\%) \\
\hline \multicolumn{4}{|l|}{ TTP } \\
\hline Patients with events & $20(74.1 \%)$ & $20(95.2 \%)$ & $3(42.9 \%)$ \\
\hline $\begin{array}{l}\text { TTP }(\text { median } \\
\text { months) }{ }^{\mathrm{a}}(95 \% \mathrm{Cl})^{\mathrm{a}}\end{array}$ & $1.7(1.4-2.1)$ & $1.7(1.4-2.1)$ & $\mathrm{I} .3$ (0.7-NR) \\
\hline \multicolumn{4}{|l|}{ OS } \\
\hline Patients with events & $26(96.3 \%)$ & & $7(100 \%)$ \\
\hline $\begin{array}{l}\text { OS (median months) } \\
(95 \% \mathrm{Cl})^{\mathrm{a}}\end{array}$ & $5.7(3.5-9.6)$ & NA & $3.9(1.8-9.6)$ \\
\hline
\end{tabular}

Note: aKaplan-Meier analysis.

Abbreviations: $\mathrm{Cl}$, confidence interval; $\mathrm{CR}$, complete response; $\mathrm{DCR}$, disease control rate; ITT, intention-to-treat population; NA, not analyzed; NR, not reached; ORR, overall response rate; OS, overall survival; PD, progressive disease; PR, partial response; RD, recommended dose population; RECIST, Response Evaluation Criteria in Solid Tumors; RESP, response population; SAF, safety population; SD, stable disease; TTP, time to progression.

clinical studies have investigated metronomic schedules using a variety of anti-neoplastic treatments including vinorelbine, cyclophosphamide, capecitabine, methotrexate, sorafenib, everolimus and temozolomide. ${ }^{31}$ However, conflicting results demonstrated the need for optimized patient selection and stratification.

This Phase I trial confirmed that NVBo can be administered safely on a daily basis with only marginal PK accumulation. In a "three weeks on, one week off" schedule, the recommended dose was found to be $30 \mathrm{mg} / \mathrm{d}$ in cycle 1 with escalation to $40 \mathrm{mg} / \mathrm{d}$ from cycle 2 , if tolerated. The results show acceptable tolerability and only marginal PK accumulation. Moreover, the observed vinorelbine blood concentrations at 30 and $40 \mathrm{mg} / \mathrm{d}$ are in the $1-10 \mathrm{ng} / \mathrm{mL}$ range $>24$ hours, which suggests that a continuous anti-angiogenic coverage is maintained using this dose regimens. ${ }^{25}$ This vinorelbine concentration range is also consistent with the previously demonstrated effect of vinorelbine with platinum to sensitize tumor cells to cytotoxic T lymphocyte-mediated lysis..$^{32}$ More broadly, while sparing the cytotoxic $\mathrm{T}$ cells, vinorelbine daily metronomic administration may continuously stimulate the maturation of dendritic cells and kill the immunosuppressive Treg cells, as was described for related chemotherapeutic agents. ${ }^{33,34}$ On the contrary, those effects may be triggered only episodically with conventional dosing regimen, for which there are higher $\mathrm{C}_{\max }$ and larger peak/trough fluctuations of circulating concentrations. ${ }^{35,36}$

Because vinorelbine is predominantly metabolized by hepatic CYP3A $4,{ }^{37}$ drug exposure may be higher in patients with impaired liver function. Patients with significantly impaired liver function were excluded from this study. This study included many patients who had undergone one or more lines of systemic chemotherapy. Although this population is clinically relevant, the MTD established in this setting may be lower than in a treatment-naive, first-line population. Careful investigation of the safety and efficacy in specific populations and treatment situations is required in future studies.

As this study was not primarily designed to assess efficacy of the tested treatment, efficacy results must be interpreted with caution, especially taking into account the extensive and mixed pretreatment of the included patient population. Considering these limitations, the observed results - with a DCR of $19.0 \%$, a median TTP of 1.7 months and a median OS of 5.7 months - provide an initial signal with regard to clinical activity of the investigated regimen. The observed disease stabilization and lack of partial or complete responses in this study should be interpreted with consideration of the heavy pretreatment of most patients included. A retrospective analysis of third-line chemotherapy by Girard et $\mathrm{al}^{38}$ described a response rate of $38 \%$ after first-line treatment but only $14 \%$ and $6 \%$ after second- and third-line treatments, respectively. In contrast, the rate of disease stabilization following thirdline treatment was 30\% and cancer-related symptoms and performance status improved during third-line treatment for many patients. A decreasing response rate with increasing number of lines of treatment was also reported in the large retrospective study by Massarelli et al ${ }^{39}$ who showed thirdline response rates of only $2.3 \%$ and fourth-line response rates of $0 \%$ in contrast to first-line response rates over $20 \%$. These results demonstrate that a low response rate is often seen following the administration of treatments in third or later line and should not in itself discourage further trials of a treatment. In this study, there was significant heterogeneity in the responses observed, as shown by the wide $95 \%$ CI for DCR (4.9-27.3 months), with some patients benefiting with $>2$ years of stable disease control. Molecular and clinical predictors of response to metronomic vinorelbine have yet to be established. Future clinical trials of metronomic vinorelbine should include the search for potential predictors of response in clearly defined patient populations.

Several other recent trials have investigated and further ongoing trials are currently evaluating the metronomic application of NVBo in solid tumors. In a recent Phase I-II 
study of metronomic NVBo plus capecitabine in patients with metastatic breast cancer, the MTD for NVBo was found to be $40 \mathrm{mg}$ three times per week, combined with capecitabine $500 \mathrm{mg}$ three times per day from days 1-14 of a 21-day cycle. Initial efficacy data revealed a clinical benefit in $58.1 \%$ of the patients. ${ }^{26}$ In addition, Briasoulis et $\mathrm{al}^{25}$ investigated a metronomic NVBo monotherapy in patients with various advanced solid tumors and suggested a NVBo dose of $50 \mathrm{mg}$ given three times per week. This schedule was further investigated as firstline and salvage treatment in NSCLC by Camerini et $a 1,{ }^{40}$ who demonstrated a clinical benefit in $58.1 \%$ of patients treated in first line, with a median TTP and OS of 5 and 9 months, respectively. As salvage treatment, this regimen showed a median TTP and OS of 2.2 and 9.4 months, respectively. ${ }^{41}$ An adequate tolerability profile was observed in all of these studies. Subsequent Phase II studies investigating the three times per week as well as the continuous daily administration of metronomic NVBo in patients with metastatic breast cancer and advanced NSCLC are currently ongoing (EudraCT 2014-003860-19, EudraCT 2014-003859-61, NCT03007992). The exclusion of the chemotherapy-free week in these regimens may provide more continuous anti-neoplastic activity and offer additional biological benefit.

\section{Conclusion}

The results from this Phase I study in mostly extensively pretreated patients with advanced NSCLC show that daily administration of NVBo is feasible and safe at the recommended dose level (30-40 mg/d). PK assessment indicated that blood concentrations of vinorelbine after daily administration are continuously maintained at rather low levels, which would have a potential to trigger anti-angiogenic and immune-mediated antitumor mechanisms. Further studies are warranted to evaluate the efficacy and to further characterize the safety of this novel approach.

\section{Acknowledgments}

This study was designed, initiated, conducted and analyzed under the responsibility of the University Hospital of Munich, the sponsor of this trial. The project was supported by an unrestricted grant as well as by free-of-charge medication provided by Pierre Fabre Pharma GmbH, Freiburg, Germany. Moreover, Pierre Fabre Pharma GmbH also provided financial support for medical writing assistance and scientific input during the manuscript preparation. The authors also would like to thank the patients for their participation, the staff of the study sites and the clinical research organization ClinAssess GmbH (Leverkusen, Germany), all of whom significantly contributed to the success of the study. We further thank Dr Schreier and Dr Esser at co.faktor GmbH (Berlin, Germany), who provided medical writing assistance.

\section{Disclosure}

AT received conference registration and travel support from Pierre Fabre Pharma GmbH. PF is an employee of Pierre Fabre Pharmaceuticals (Toulouse, France), BE is an employee of Pierre Fabre Pharma GmbH (Freiburg, Germany) and $\mathrm{RMH}$ received funding from Pierre Fabre Pharma GmbH (Freiburg, Germany). The other authors report no conflicts of interest in this work.

\section{References}

1. Ferlay J, Soerjomataram I, Ervik M, et al [homepage on the Internet]. GLOBOCAN 2012 - Lung cancer incidence and mortality worldwide. Available from: http://globocan.iarc.fr. Accessed September 15, 2015.

2. Stewart BW, Wild CP. World Cancer Report 2014. Lyon, France: International Agency for Research on Cancer (IARC) - World Health Organization; 2014.

3. Clinical practice guidelines for the treatment of unresectable non-smallcell lung cancer. Adopted on May 16, 1997 by the American Society of Clinical Oncology. J Clin Oncol. 1997;15(8):2996-3018.

4. Molina JR, Yang P, Cassivi SD, Schild SE, Adjei AA. Non-small cell lung cancer: epidemiology, risk factors, treatment, and survivorship. Mayo Clin Proc. 2008;83(5):584-594.

5. Le Chevalier T, Brisgand D, Douillard JY, et al. Randomized study of vinorelbine and cisplatin versus vindesine and cisplatin versus vinorelbine alone in advanced non-small-cell lung cancer: results of a European multicenter trial including 612 patients. J Clin Oncol. 1994; 12(2):360-367.

6. Depierre A, Chastang C, Quoix E, et al. Vinorelbine versus vinorelbine plus cisplatin in advanced non-small cell lung cancer: a randomized trial. Ann Oncol. 1994;5(1):37-42.

7. Crawford J, O'Rourke M, Schiller JH, et al. Randomized trial of vinorelbine compared with fluorouracil plus leucovorin in patients with stage IV non-small-cell lung cancer. J Clin Oncol. 1996;14(10): 2774-2784.

8. Wozniak AJ, Crowley JJ, Balcerzak SP, et al. Randomized trial comparing cisplatin with cisplatin plus vinorelbine in the treatment of advanced non-small-cell lung cancer: a Southwest Oncology Group study. J Clin Oncol. 1998;16(7):2459-2465.

9. Le Chevalier T, Brisgand D, Soria JC, et al. Long term analysis of survival in the European randomized trial comparing vinorelbine/cisplatin to vindesine/cisplatin and vinorelbine alone in advanced non-small cell lung cancer. Oncologist. 2001;6(suppl 1):8-11.

10. Manegold C. Chemotherapy for advanced non-small cell lung cancer: standards. Lung Cancer. 2001;34(suppl 2):S165-S170.

11. Reck M, Popat S, Reinmuth N, et al. Metastatic non-small-cell lung cancer (NSCLC): ESMO Clinical Practice Guidelines for diagnosis, treatment and follow-up. Ann Oncol. 2014;25(suppl 3):ii27-ii39.

12. Besse B, Adjei A, Baas P, et al; Panel Members; ESMO. 2nd ESMO Consensus Conference on Lung Cancer: non-small-cell lung cancer first-line/second and further lines of treatment in advanced disease. Ann Oncol. 2014;25(8):1475-1484.

13. Findlay M, von Minckwitz G, Wardley A. Effective oral chemotherapy for breast cancer: pillars of strength. Ann Oncol. 2008;19(2): 212-222.

14. Twelves C, Gollins S, Grieve R, Samuel L. A randomised cross-over trial comparing patient preference for oral capecitabine and 5-fluorouracil/leucovorin regimens in patients with advanced colorectal cancer. Ann Oncol. 2006;17(2):239-245. 
15. Liu G, Franssen E, Fitch MI, Warner E. Patient preferences for oral versus intravenous palliative chemotherapy. J Clin Oncol. 1997;15(1): $110-115$.

16. Cassidy J, Douillard JY, Twelves C, et al. Pharmacoeconomic analysis of adjuvant oral capecitabine vs intravenous 5-FU/LV in Dukes' C colon cancer: the X-ACT trial. Br J Cancer. 2006;94(8):1122-1129.

17. Kerbel RS, Kamen BA. The anti-angiogenic basis of metronomic chemotherapy. Nat Rev Cancer. 2004;4(6):423-436.

18. Torimura T, Iwamoto H, Nakamura T, et al. Metronomic chemotherapy: possible clinical application in advanced hepatocellular carcinoma. Transl Oncol. 2013;6(5):511-519.

19. Bocci G, Kerbel RS. Pharmacokinetics of metronomic chemotherapy: a neglected but crucial aspect. Nat Rev Clin Oncol. 2016;13(11): 659-673.

20. Tan EH, Rolski J, Grodzki T, et al. Global Lung Oncology Branch trial 3 (GLOB3): final results of a randomised multinational phase III study alternating oral and i.v. vinorelbine plus cisplatin versus docetaxel plus cisplatin as first-line treatment of advanced non-small-cell lung cancer. Ann Oncol. 2009;20(7):1249-1256.

21. De Lena MD, Ramlau R, Hansen O, et al. Phase II trial of oral vinorelbine in combination with cisplatin followed by consolidation therapy with oral vinorelbine in advanced NSCLC. Lung Cancer. 2005;48(1):129-135

22. Gralla RJ, Gatzemeier U, Gebbia V, Huber R, O’Brien M, Puozzo C. Oral vinorelbine in the treatment of non-small cell lung cancer: rationale and implications for patient management. Drugs. 2007;67(10):1403-1410

23. Jassem J, Kosmidis P, Ramlau R, et al. Oral vinorelbine in combination with cisplatin: a novel active regimen in advanced non-small-cell lung cancer. Ann Oncol. 2003;14(11):1634-1639.

24. Freyer G, Delozier T, Lichinister M, et al. Phase II study of oral vinorelbine in first-line advanced breast cancer chemotherapy. J Clin Oncol. 2003;21(1):35-40.

25. Briasoulis E, Aravantinos G, Kouvatseas G, et al. Dose selection trial of metronomic oral vinorelbine monotherapy in patients with metastatic cancer: a hellenic cooperative oncology group clinical translational study. BMC Cancer. 2013;13:263.

26. Cazzaniga ME, Torri V, Villa F, et al. Efficacy and safety of the all-oral schedule of metronomic vinorelbine and capecitabine in locally advanced or metastatic breast cancer patients: the phase I-II VICTOR-1 study. Int J Breast Cancer. 2014;2014:7. Article ID 769790.

27. Addeo R, Sgambato A, Cennamo G, et al. Low-dose metronomic oral administration of vinorelbine in the first-line treatment of elderly patients with metastatic breast cancer. Clin Breast Cancer. 2010;10(4):301-306

28. Pallis AG, Chandrinos V, Pavlakou G, et al. A multicenter phase I trial of metronomic oral vinorelbine plus cisplatin in patients with NSCLC. Cancer Chemother Pharmacol. 2011;67(6):1239-1245.

29. DCTD, NCI, NIH, DHHS. Cancer Therapy Evaluation Program, Common Terminology Criteria for Adverse Events (CTCAE), Version 3.0, 2003; 2006. Available from: http://ctep.cancer.gov/ protocolDevelopment/electronic_applications/docs/ctcaev3.pdf. Accessed December 19, 2016.
30. Therasse P, Arbuck SG, Eisenhauer EA, et al. New guidelines to evaluate the response to treatment in solid tumors. European Organization for Research and Treatment of Cancer, National Cancer Institute of the United States, National Cancer Institute of Canada. J Natl Cancer Inst. 2000;92(3):205-216.

31. Gnoni A, Silvestris N, Licchetta A, et al. Metronomic chemotherapy from rationale to clinical studies: a dream or reality? Crit Rev Oncol Hematol. 2015;95(1):46-61.

32. Gameiro SR, Caballero JA, Hodge JW. Defining the molecular signature of chemotherapy-mediated lung tumor phenotype modulation and increased susceptibility to T-cell killing. Cancer Biother Radiopharm. 2012;27(1):23-35.

33. Tanaka H, Matsushima H, Nishibu A, Clausen BE, Takashima A. Dual therapeutic efficacy of vinblastine as a unique chemotherapeutic agent capable of inducing dendritic cell maturation. Cancer Res. 2009;69(17):6987-6994.

34. Tagliamonte M, Petrizzo J, Napolitano M, et al. A novel multi-drug metronomic chemotherapy significantly delays tumor growth in mice. J Transl Med. 2016;14:58

35. Bourgeois H, Vermorken J, Dark G, et al. Evaluation of oral versus intravenous dose of vinorelbine to achieve equivalent blood exposures in patients with solid tumours. Cancer Chemother Pharmacol. 2007;60(3):407-413.

36. Khayat D, Rixe O, Brunet R, et al. Pharmacokinetic linearity of i.v. vinorelbine from an intra-patient dose escalation study design. Cancer Chemother Pharmacol. 2004;54(3):193-205.

37. Kajita J, Kuwabara T, Kobayashi H, Kobayashi S. CYP3A4 is mainly responsible for the metabolism of a new vinca alkaloid, vinorelbine, in human liver microsomes. Drug Metab Dispos. 2000; 28(9):1121-1127.

38. Girard N, Jacoulet P, Gainet M, et al. Third-line chemotherapy in advanced non-small cell lung cancer: identifying the candidates for routine practice. J Thorac Oncol. 2009;4(12):1544-1549.

39. Massarelli E, Andre F, Liu DD, et al. A retrospective analysis of the outcome of patients who have received two prior chemotherapy regimens including platinum and docetaxel for recurrent non-small-cell lung cancer. Lung Cancer. 2003;39(1):55-61.

40. Camerini A, Puccetti C, Donati S, et al. Metronomic oral vinorelbine as first-line treatment in elderly patients with advanced non-small cell lung cancer: results of a phase II trial (MOVE trial). BMC Cancer. 2015; $15: 359$.

41. Kontopodis E, Hatzidaki D, Varthalitis I, et al. A phase II study of metronomic oral vinorelbine administered in the second line and beyond in non-small cell lung cancer (NSCLC): a phase II study of the Hellenic Oncology Research Group. J Chemother. 2013;25(1):49-55.
OncoTargets and Therapy

\section{Publish your work in this journal}

OncoTargets and Therapy is an international, peer-reviewed, open access journal focusing on the pathological basis of all cancers, potential targets for therapy and treatment protocols employed to improve the management of cancer patients. The journal also focuses on the impact of management programs and new therapeutic agents and protocols on

\section{Dovepress}

patient perspectives such as quality of life, adherence and satisfaction. The manuscript management system is completely online and includes a very quick and fair peer-review system, which is all easy to use. Visit http://www.dovepress.com/testimonials.php to read real quotes from published authors. 